\title{
Avaliação de desempenho acústico de um consultório odontológico
}

\author{
Júlio César Fernandes ${ }^{\mathrm{a}, *}$, Larissa Nascimento dos Santos ${ }^{\mathrm{b}}$, \\ Homero Jorge Matos de Carvalho ${ }^{c}$ \\ a,*julio_dsi@yahoo.com.br, IFPB, Brasil \\ blarissa.di.santos@hotmail.com, IFPB, Brasil \\ chomerojmc@uol.com.br, IFPB, Brasil
}

\begin{abstract}
Resumo
Este trabalho tem por objetivo a avaliação acústica de um consultório odontológico situado na cidade de João Pessoa (PB), considerando diversas situações de utilização do espaço. Foi realizado a partir de levantamento físico do ambiente, da identificação das atividades desenvolvidas, da identificação das fontes externas e internas de ruídos e da medição dos níveis destes. Estes últimos foram comparados com a NBR 10.152 (ABNT, 1987). Em seguida, foram realizados cálculos do isolamento acústico e do tempo de reverberação para a elaboração de soluções corretivas do problema encontrado. Constatou-se que o ambiente não atende aos parâmetros acústicos e que, apesar de os níveis de ruído medidos não causarem danos à saúde dos usuários, provocam desconforto.
\end{abstract}

Palavras-chave

Conforto acústico. Consultório odontológico. Isolamento acústico. Reverberação.

\section{Introdução}

Em consultórios odontológicos há uma rotina de trabalho intensa, e os profissionais da área sofrem por trabalhar em condições não ideais, principalmente em razão de problemas posturais, além de ruídos provenientes dos equipamentos e do exterior, comprometendo sua saúde física, em especial a audição, o que pode afetar o estado psicológico e, consequentemente, a produtividade. Dessa maneira, a análise ergonômica da atividade do cirurgiãodentista requer a avaliação acústica do ambiente ao qual ele e os seus pacientes estão expostos.

A preocupação dos dentistas com a perda auditiva induzida pelo ruído (PAIR) começou apenas na década de 50, quando surgiram os equipamentos de alta rotação movidos por turbinas que, por sua vez, produziam ruídos de alta intensidade. A PAIR constitui-se em doença profissional de enorme prevalência nas comunidades urbanas industrializadas, sendo decorrente da exposição contínua a níveis elevados de pressão sonora (PARAGUAY, 1999).
Basicamente, há dois tipos de ruído: o contínuo - de longa duração - e o de impacto - de curta duração. Ambos acabam sendo produzidos na própria atividade desempenhada pelo indivíduo ou em seu entorno. Assim, os ruídos podem ser diferenciados em ruído de atividade e de fundo, respectivamente.

0 ruído de impacto parece ser mais prejudicial à produtividade e oferecer mais riscos de acidentes, principalmente quando é inesperado. Segundo lida (2005, p. 505),

[...] um som repentino de $100 \mathrm{~dB}$, com duração aproximada de 5 minutos, provoca um susto, produzindo uma reação imediata de defesa - quando o organismo adota uma posição de máxima estabilidade postural. Esse tipo de reação interfere no trabalho e retarda o tempo de reação para outras tarefas.

Essa reação pode causar, inclusive, acidentes graves em operadores de máquinas, por exemplo.

0 fato de o ruído de impacto causar maior preocupação deve-se à capacidade que o organismo tem de se adaptar ao ruído contínuo. Após certo 
período de exposição, o indivíduo se torna menos sensivel a esse ruído (IIDA, 2005).

De todo modo, a exposição excessiva aos ruídos pode provocar sequelas em outros órgãos, além do auditivo, como transtornos de comunicação, comportamentais, neurológicos, vestibulares, digestivos, cardiovasculares, entre outros.

$\mathrm{Na}$ atividade de odontologia, os ruídos intensos prejudicam as tarefas que exigem concentração mental, atenção, velocidade e precisão de movimentos, de modo que, quanto maior o tempo de exposição do indivíduo a essas condições, maiores serão as consequências.

Para regular as condições de exposição das pessoas aos ruídos, a Associação Brasileira de Normas Técnicas (ABNT) criou a norma NBR 10.152 (ABNT, 1987) Acústica - Avaliação do ruído ambiente em recintos de edificações visando o conforto dos usuários - Procedimento, que estabelece limites para os ruídos de fundo nos ambientes construídos, objetivando o conforto acústico. Essa norma é indicada, inclusive, pela NR-17 (Ergonomia) (NORMA..., 1990) ao relacionar o problema acústico a problemas ergonômicos da atividade de trabalho.

No caso dos consultórios odontológicos, a NBR 10.152 (ABNT, 1987) estabelece um limite de 35 a $45 \mathrm{~dB}(\mathrm{~A})$ na sala de atendimento, e de 40 a $50 \mathrm{~dB}$ na sala de espera, sendo o primeiro valor o de conforto, e o segundo o limite admissível para o ruído.

Com relação ao tempo de exposição ao ruído, seja ele de fundo ou de tarefa, a NR-15 estabelece limites de tolerância para o ruído contínuo ou intermitente ao qual poderá estar exposto um trabalhador, tendo como base o limite de 8 horas (jornada de trabalho) para o nível de ruído de $85 \mathrm{~dB}$ (Tabela 1). Acima desse nível, deve-se diminuir o tempo de exposição. No entanto, acima de $115 \mathrm{~dB}$, recomenda-se o uso de equipamentos de proteção individual (11DA, 2005).

Embora a NR-15 indique que esse nível de ruído por até 8 horas não cause dano à saúde humana, poderá causar desconforto (LACERDA et al., 2002), com consequências negativas para a produtividade. Segundo Barros (1991), o ruído foi apontado pelos dentistas como um fator gerador de estresse no exercício da odontologia.
0 profissional dentista permanece grande parte do tempo nas salas do consultório, que devem reunir um conjunto de condições propícias de conforto e ergonomia para que seu trabalho seja produtivo, e sejam evitadas as enfermidades ocupacionais.

Tôrres (2007) verificou que 96\% dos acadêmicos do curso de Odontologia da Universidade Federal do Rio Grande do Norte, entrevistados em uma pesquisa, percebem o ruído durante o atendimento clínico. Desse quantitativo, 28,1\% se sentem incomodados.

Para Naressi (1983 apud Lacerda et al., 2002), os ruídos devem situar-se entre 60 e $70 \mathrm{~dB}$. Se estes se apresentam entre 70 e $80 \mathrm{~dB}$, aumenta a sensação de desconforto; acima de $90 \mathrm{~dB}$, há grande risco para a acuidade auditiva.

Essa condição é difícil de ser atingida, devido ao ruído produzido pelos equipamentos odontológicos, especialmente a caneta de alta rotação (utilizada nas obturações). Estes chegam a atingir, em média, 80,5 dB (TÔRRES, 2007; LACERDA et al., 2002), alguns superando a barreira dos $85 \mathrm{~dB}$ (LACERDA et al., 2002).

Betoli e Carneiro (2004) observaram, em vários consultórios odontológicos, que os aparelhos de ar-condicionado muito contribuem para a elevação do nível sonoro nas baixas frequências (graves), enquanto que o motor dos aparelhos odontológicos aumenta a intensidade dos sons nas altas frequências (agudos). Como o ouvido humano é mais sensivel aos sons agudos, o ruído do motor se sobressai em relação aos demais equipamentos.

Além do profissional odontólogo, há que se considerar o paciente. Para a maioria das pessoas, a visita ao dentista tem uma conotação psicológica bastante negativa. 0 ruído emitido pela caneta de alta rotação não é apenas irritante, mas causa uma intimidação individual. 0 temor provocado pelo ruído é muito reconhecido dentro dos consultórios odontológicos, no entanto seu efeito psicológico tem sido muito pouco considerado nos estudos de acústica e de ergonomia nessa atividade.

A espera pelo atendimento em condições nas quais é possível ouvir o ruído provocado pela referida caneta pode aumentar a ansiedade e o medo em muitos pacientes. Estes, ao serem atendidos, tendem a contrair seus músculos, principalmente os da face e da mandíbula, quando o motor é acionado, dificultando o acesso do dentista à sua boca.

Tabela 1 . Limites de tolerância para o ruído contínuo ou intermitente.

\begin{tabular}{|c|c|c|c|c|c|c|c|c|c|c|c|c|c|c|c|c|c|c|c|c|c|c|c|}
\hline \multicolumn{24}{|c|}{ Nível de ruído dB $(\mathrm{A})$} \\
\hline & 85 & 86 & 87 & 88 & 89 & 90 & 91 & 92 & 93 & 94 & 95 & 96 & 98 & 100 & 102 & 104 & 105 & 105 & 108 & 110 & 112 & 114 & 115 \\
\hline $\begin{array}{l}\text { Máxima exposição } \\
\text { diária permissível } \\
\text { (minutos) }\end{array}$ & 480 & 420 & 360 & 300 & 270 & 240 & 210 & 180 & 160 & 135 & 120 & 105 & 75 & 60 & 45 & 35 & 30 & 25 & 20 & 15 & 10 & 8 & 7 \\
\hline
\end{tabular}


Essa condição pode afetar a atividade do dentista, tanto na sua produtividade - pois, em muitos casos, é necessário um tempo maior para o paciente relaxar e permitir o tratamento -, quanto na qualidade do serviço, pois pode ter a precisão diminuída em razão do ruído e das dificuldades impostas pelo paciente em estado de estresse e medo.

Embora o ruído seja o agente mais difuso no consultório odontológico, os esforços para controlá-lo são limitados, fazendo-se necessária a criação de ambientes adaptados ao cirurgião-dentista, tendo este o papel de monitorar o ambiente, identificando os problemas e acionando as medidas de controle e/ou corretivas (LOPES, 1995; BUSCHINELLI, 1994 apud PARAGUAY, 1999).

Enquanto se espera pelo desenvolvimento de novas técnicas de tratamento e de equipamentos mais silenciosos, a arquitetura pode contribuir para minimizar o problema através de medidas preventivas. Segundo lida (2005), para diminuir o ruído industrial, por exemplo, as possibilidades são: atenuar na fonte; isolar a fonte; reduzir a reverberação; remover o trabalhador; adotar controles administrativos; e proteger o trabalhador através do uso de protetores auriculares. Dessas alternativas, a arquitetura poderá contribuir através do isolamento acústico de fontes ruidosas (isolando a sala de recepção da de atendimento, por exemplo) e da especificação do uso de materiais mais absorventes, que reduzam o tempo de reverberação do som no ambiente e atenuem sua intensidade.

A importância da acústica arquitetônica na solução do problema é percebida, inclusive, por profissionais e estudantes de Odontologia. No estudo realizado por Tôrres (2007), 21,3\% dos alunos de Odontologia da UFRN indicaram o planejamento da clínica como uma das alternativas para a prevenção da PAIR.

Bertoli e Carneiro (2004) verificaram que os consultórios que possuiam corredores ou outros ambientes separando a sala de espera da de atendimento tinham melhor desempenho acústico. Da mesma maneira ocorreu com aqueles consultórios cuja sala de atendimento estava mais recuada em relação à rua.

$\mathrm{Na}$ fase de projeto - de uma edificação nova ou de intervenção corretiva de uma edificação existente -, a adequação acústica é possível através de simulações do isolamento acústico e do tempo de reverberação através de cálculos específicos. No caso do isolamento, são considerados a área dos elementos construtivos a serem isolados (parede, teto, piso etc.), os índices de isolamento acústico dos componentes que constituem esses elementos, a intensidade do som a ser isolado e as frequências das ondas que compõem esse som.
No caso do tempo de reverberação, deve-se considerar o volume interno do ambiente, o número de pessoas que o utilizam, a capacidade de absorção de todas as superfícies existentes no local, inclusive do mobiliário, as atividades desenvolvidas no ambiente e as frequências do som produzido em seu interior. A partir do volume do ambiente e da atividade desenvolvida, é possível, através do gráfico de BoltBeranekand Newman (CARVALHO, 2006), identificar o tempo ótimo de reverberação (tor) para o ambiente que estiver sendo avaliado, para frequência de $500 \mathrm{~Hz}$, a partir do qual, utilizando-se uma equação logarítmica, acha-se o tor para as demais frequências.

0 tor serve de referência para a avaliação do tempo de reverberação real (tr), calculado a partir das demais características do ambiente (área e coeficiente de absorção das superfícies e número de pessoas). Para se ter uma reverberação ideal, o tr calculado só poderá variar em 10\% (para mais ou para menos) em relação ao tor $(0,9$ tor $\leq \operatorname{tr} \leq 1,1$ tor $)$.

A reverberação é importante porque o som ouvido é uma composição do som emitido diretamente pela fonte ao ouvido humano e daquele refletido pelas superfícies do ambiente. Assim, em ambiente com muita reverberação, o som ouvido pode ter intensidade maior do que o emitido pela fonte, podendo ser maior em até $6 \mathrm{~dB}$ (CARVALHO, 2006).

Como o gráfico de BoltBeranekand Newman não estabelece o tor para consultórios odontológicos ou para ambiente similar, neste trabalho adotou-se o tor $\leq 0,2 \mathrm{~s}$, tendo em vista que o seu objetivo é atenuar ao máximo possível as reflexões existentes no ambiente.

Diante desse contexto, este trabalho avalia a qualidade acústica de um consultório odontológico situado em João Pessoa, verificando os níveis de ruído e o tempo de exposição aos quais estão submetidos pacientes e dentista, o que serviu de base para a formulação de uma alternativa de correção do ambiente.

\section{Descrição do objeto de estudo}

0 consultório odontológico localiza-se na cidade de João Pessoa (PB), em uma avenida de grande fluxo de veículos, portanto com altos níveis de pressão sonora. Funciona das $9 \mathrm{~h}$ às $13 \mathrm{~h}$ e das $15 \mathrm{~h} 30$ às 20h. Cada atendimento tem duração média de meia hora.

O consultório odontológico é composto por uma sala de atendimento e uma de espera. A primeira é o ambiente onde o paciente recebe o tratamento odontológico; a de espera, onde os pacientes são recepcionados, marcam consultas e aguardam para serem atendidos. Além desses dois 
ambientes, o consultório possui um banheiro. A sala de atendimento está montada com os equipamentos básicos para o tratamento odontológico (cadeira, bancada de instrumentação, onde estão as canetas de alta rotação, sugador e outras ferramentas, estufa, etc.) e um aparelho de ar-condicionado. Na recepção, há um birô de atendimento, cadeiras para os pacientes em espera e uma TV. 0 compressor de ar que alimenta os equipamentos fica instalado fora do consultório, no pavimento inferior, não sendo possível ouvi-lo dentro do consultório.

Normalmente, o consultório é utilizado por no máximo cinco pessoas, três delas ocupando a sala de atendimento (dentista, paciente e auxiliar).

A sala de recepção tem cerca de $7 \mathrm{~m}^{2}$, toda revestida por materiais de baixa absorção acústica e, ao mesmo tempo, edificada por componentes (paredes, teto e piso) de baixo isolamento acústico (Figuras 1 e 2). 0 piso é revestido com cerâmica; as paredes externas, em alvenaria de tijolos cerâmicos, são cobertas com argamassa, e o teto é revestido com forro de gesso, suspenso sob uma laje de concreto.

A sala de espera é separada da sala de atendimento por uma divisória de gesso com $8 \mathrm{~cm}$ de espessura, com detalhes em tijolo de vidro e uma porta de madeira oca. Essa sala tem $10,5 \mathrm{~m}^{2}$, tendo acabamento semelhante ao da sala de espera (Figuras 2 e 3).

No consultório, foram percebidos ruídos de fundo provenientes, internamente, do aparelho de ar-condicionado e, externamente, da sala de espera (conversação e TV), provocados também pelo tráfego de veículos. 0 ruído produzido pela atividade, como dito antes, tem origem nos equipamentos utilizados pelo dentista, sendo o de maior intensidade aquele provocado pela caneta de alta rotação.

Já na sala de espera, os ruídos de fundo são produzidos externamente, provenientes do consultório e do tráfego de veículos. Além desses, há nesse ambiente os ruídos provocados pelas conversas e pela TV, nesse caso relacionados à atividade de espera.

\section{Metodologia}

Esta pesquisa corresponde a um estudo de caso, cujo objetivo tem caráter explicativo, pois busca estabelecer as causas e consequências dos problemas acústicos identificados no consultório odontológico. Sua consecução se deu em cinco etapas, cujos procedimentos dependeram da natureza dos dados e das finalidades específicas, descritas a seguir.

A primeira etapa teve como finalidade levantar os dados necessários à avaliação quantitativa dos níveis de pressão sonora existentes no local, e da capacidade de isolamento da envoltória da edificação

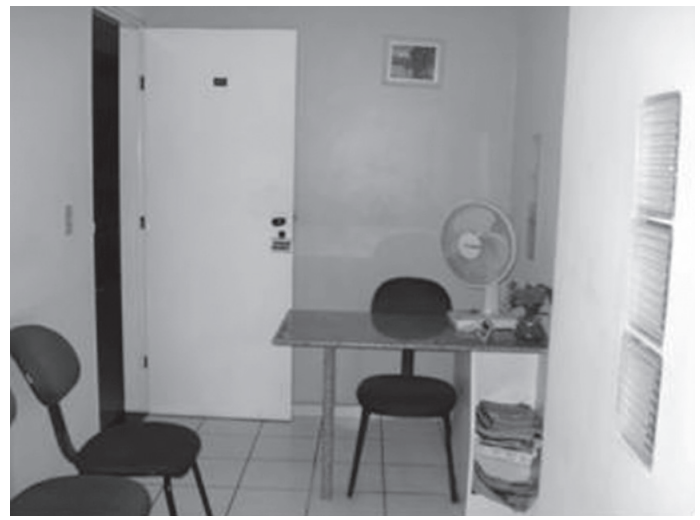

Figura 1. Sala de espera.

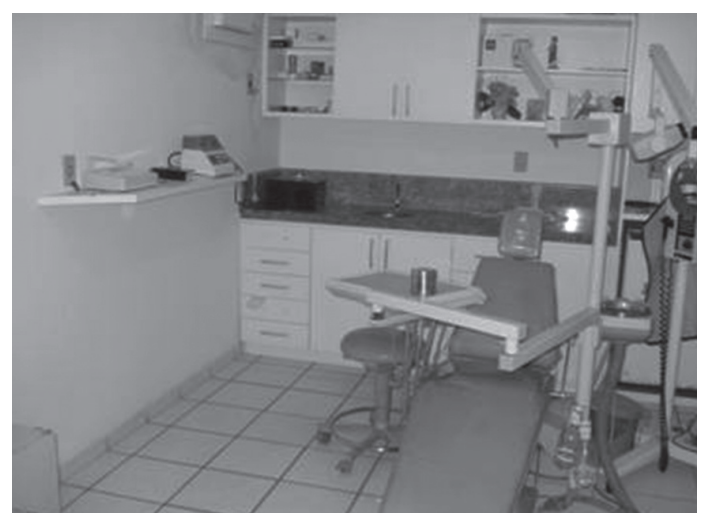

Figura 2. Sala de atendimento.

e de suas divisórias internas. Essa etapa foi, então, dividida em duas fases. Na primeira, procedeu-se o levantamento físico do ambiente, através do que foram anotadas as dimensões, as características dos materiais construtivos, o mobiliário e sua organização no espaço, as características de utilização do espaço (horários, número de pessoas, atividades etc.) e a identificação das fontes de ruído (internas e externas). A partir desses dados, foram definidos os locais e as circunstâncias em que fizeram-se levantamentos para as medições dos níveis de pressão sonora nos ambientes.

Na segunda fase, foram feitos experimentos em campo, para mensurar os níveis de pressão sonora. Em todos as medições ocorreram, simultaneamente, na fonte do ruído e nos pontos de interesse no interior do consultório (Figura 3), objetivando a verificação das condições de isolamento acústico. Foram experimentadas seis situações:

a) sala de espera com todos os equipamentos ligados, porta aberta para o exterior, sala de atendimento inativa e ruído da rua;

b) sala de atendimento com todos os equipamentos ligados, sala de espera inativa, portas e janelas fechadas, ruído da rua; 


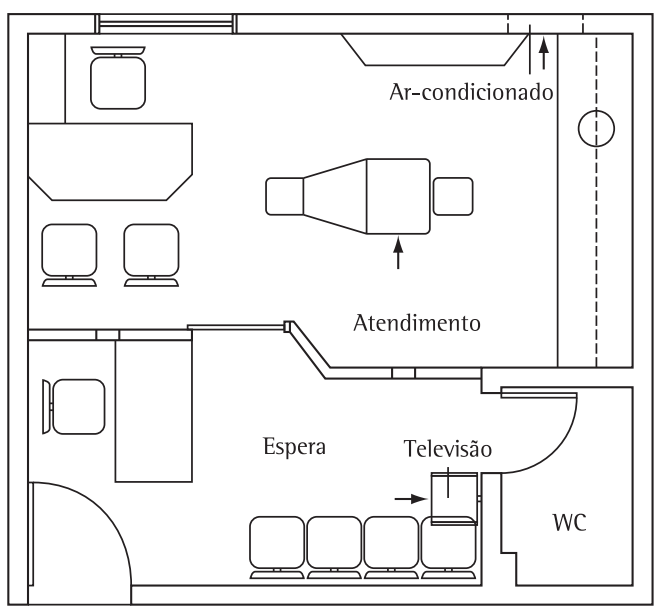

Figura 3. Layout das salas de espera e de atendimento com indicação (setas) das fontes de ruído.

c) sala de espera e sala de atendimento com equipamentos ligados e ruído da rua;

d) sala de espera com equipamentos desligados, porta aberta e ruído da rua;

e) sala de atendimento com equipamentos desligados, porta e janelas fechadas e ruído da rua; e

f) sala de espera e sala de atendimento com equipamentos ligados sem ruído da rua.

As medições foram realizadas entre $18 \mathrm{~h}$ e $19 \mathrm{~h}$, quando se coincidia o horário de atendimento com o de maior fluxo de veículos na avenida local. Foram utilizados dois decibelímetros da marca Instrutherm, operando no circuito de compensação "A" e circuito de resposta lenta (slow). A leitura dos dados foi feita durante um minuto, sendo anotado o valor mais elevado. Essa opção se ateve ao objetivo de corrigir as características arquitetônicas do ambiente para as piores condições.

Na segunda etapa, procedeu-se a tabulação dos dados medidos em campo, utilizando-se uma planilha elaborada no software Excel. Após a tabulação, foram feitas análises comparativas entre ruídos medidos na fonte e no local de interesse, identificando-se os elementos de pouca capacidade de isolamento. Em seguida, os níveis de pressão sonora dos ruídos de fundo medidos nos locais de interesse foram comparados aos níveis admissíveis estabelecidos na NBR 10.152 (ABNT, 1987), obtendo-se, assim, uma referência para o dimensionamento do isolamento necessário à adequação acústica do consultório.

$\mathrm{Na}$ terceira etapa, foi realizada uma avaliação mais minuciosa, através de simulações computacionais (planilha elaborada software Excel), pelas quais se calcularam o isolamento e o tempo de reverberação (método de Sabine) para cada ambiente, considerando as frequências de 125, 500 e $2000 \mathrm{~Hz}$. Os resultados dessas simulações foram comparados aos parâmetros estabelecidos nas normas vigentes (isolamento) e na literatura especializada (tempo de reverberação), permitindo a identificação e a avaliação das causas dos problemas acústicos identificados nas medições realizadas na segunda etapa.

A quarta etapa foi destinada à avaliação qualitativa do ambiente, feita a partir da opinião dos usuários do consultório odontológico (4 pacientes, 1 atendente e 1 odontólogo), tomada através de entrevistas semiestruturadas, cujo teor buscou levantar dados sobre a percepção do ruído, os possíveis sintomas de doenças causadas pela exposição e a influência do ruído no tratamento dentário. Os resultados das entrevistas foram relacionados aos da avaliação quantitativa, mostrando as repercussões do problema na saúde do odontólogo, no estresse do paciente e no desenvolvimento da atividade.

$\mathrm{Na}$ quinta etapa, repetiram-se os procedimentos da quarta etapa para simular uma proposta de correção acústica do ambiente analisado, os quais nortearam a elaboração de um projeto de interior para o local.

\section{Resultados}

Os resultados estão apresentados em três partes. A primeira descreve a percepção do ruído pelos pesquisadores e usuários do ambiente. A segunda indica os níveis de ruído medidos e a sua comparação com os níveis estabelecidos pela norma. A terceira mostra os resultados dos cálculos de isolamento acústico e do tempo de reverberação para a situação existente e para uma intervenção corretiva no projeto arquitetônico.

\subsection{Percepção do ruído}

0 ruído mais intenso identificado no interior do consultório odontológico é o provocado pela caneta de alta rotação, confirmando a observação feita por Tôrres (2007). Esse ruído se propaga numa intensidade suficiente para atravessar a parede que separa as duas salas. Dessa maneira, os pacientes em espera acabam ficando apreensivos e incomodados com o ruído. Para alguns deles, o ruído provoca medo. Ao ser questionada se os pacientes se queixam do ruido provocado pela turbina de alta rotação, a odontóloga responsável pelo consultório respondeu:"Eles geralmente associam o barulho da broca à dor; acham que vão sentir dor antes de começar o tratamento". Embora consiga contornar o estresse do paciente provocado pelo ruído e medo - dizendo que "o ruído não dór" -, a profissional considera que, se a caneta fosse silenciosa, os pacientes sentiriam menos medo. 
Um de seus pacientes entrevistados revelou que o ruído e a dor sentida durante a obturação lhe causavam incômodo na mesma proporção, pois possuía trauma de infância. Esse mesmo paciente, ao ser questionado sobre sua reação ao ouvir o ruído da turbina de alta rotação durante a espera e como se sentia antes e após a dentista acionar o motor quando estava sendo atendido, respondeu:

"Hoje, fico esperando, mas há 20 anos atrás muitas vezes já fui embora."(...) "Antes apavorada, e após, como se me livrasse de um grande peso." Paciente 1.

Outro paciente respondeu:

“Agonia." (...) “Antes me sinto com um pouco de medo e agonia, depois apavorada." Paciente 2.

Outros pacientes, embora não se sintam psicologicamente incomodados com o ruído, se queixaram do incômodo físico quando expostos por muito tempo a ele.

A odontóloga, por sua vez, se sente irritada após uma jornada de trabalho, porém, mesmo após 27 anos de profissão, não percebe nenhum sintoma físico relacionado aos ruídos existentes no consultório. Esse comentário corrobora a afirmação de lida (2005) sobre a capacidade do organismo humano de se adaptar ao ruído contínuo.

"Pode ser que interfira e cause danos à minha saúde, mas nunca parei para distinguir o que realmente interfere e procurar melhorar, acabei me acostumando." Odontóloga.

Ainda segundo essa profissional, as condições de ruído já foram piores, quando o compressor era instalado no interior do consultório.

"Por passar muitos anos com o compressor dentro do consultório, acabei ficando com excesso de irritabilidade. Quando mudei e coloquei fora, diminuiu 50\% do barulho, ficou somente o da caneta de rotação. Mas devo ficar com sequelas na audição por vários motivos, inclusive tempo de trabalho." Odontóloga.

Outros ruídos são percebidos com menos intensidade, a exemplo dos provocados pelo ar-condicionado, por outros equipamentos odontológicos e pela conversação na sala de espera. Esse último, para a odontóloga, é o que algumas vezes interfere em sua atividade, tendo que interromper o atendimento para pedir silêncio.

“As conversas na sala de espera acabam passando para a minha sala, e escuto todas as conversas. Se se exaltarem muito, acabo saindo para pedir silêncio." Odontóloga.

Quanto aos ruídos externos, o consultório - por se localizar próximo a uma avenida de grande fluxo de pessoas e automóveis - está exposto a diversos níveis de sons (Figura 4). 0 ruído provocado pelos veículos, principalmente os de grande porte (ônibus e caminhões), chega a interferir na conversação na sala de espera e na compreensão do que está sendo dito na televisão. Consequentemente, as pessoas tendem a aumentar o volume da voz e da TV, cujo som se propaga com maior intensidade para o interior da sala de atendimento, causando desconforto ao dentista.

Os ruídos externos penetram no consultório, principalmente pela janela da sala de atendimento (a), mesmo permanecendo fechada por todo tempo. Também penetra pela porta de acesso ao consultório (b), situada na recepção e que permanece aberta durante a maior parte do tempo (Figura 5).

Como se observa, a percepção do ruído é muito particular, dependendo de muitos fatores físicos e psicológicos individuais. Entretanto, mesmo não sendo percebido ou relacionado a patologias, o ruído deve ser controlado.

\subsection{Níveis de ruído identificados}

Os níveis de ruído medidos para as condições descritas na metodologia indicam que o ambiente está em condições inadequadas, do ponto de vista da acústica, devido ao nível elevado do som emitido pelas fontes sonoras e à baixa capacidade de isolamento das divisórias e absorção das superfícies.

$\mathrm{Na}$ Tabela 2 estão descritos os níveis de ruído medidos no consultório odontológico nas condições consideradas na pesquisa. Percebe-se que o nível de ruído mais elevado tem origem no tráfego de veículos (84,4 a $84,9 \mathrm{~dB})$ à frente da edificação onde se situa o consultório. Esse ruído atinge a sala de espera cerca de $10 \mathrm{~dB}$ mais baixo, mesmo assim mantendo-se acima do limite admissível (50 dB). Na sala de atendimento, com porta e janela fechadas, o ruído chega com $30 \mathrm{~dB}$ a menos, atingindo 55 $\mathrm{dB}$, também acima do limite admissível ( $45 \mathrm{~dB}$ ). Esse resultado revela a baixa capacidade de isolamento da envoltória da edificação frente ao ruído ao qual está exposta, requerendo, portanto, uma correção.

Internamente, observa-se que, quando os equipamentos estão ligados nas duas salas, o ruído atinge quase $80 \mathrm{~dB}$ na sala de espera, condição acima do limite de conforto e extremo para uma jornada de 8 horas de trabalho. Na sala de atendimento, o ruído é um pouco inferior (73 dB), porém acima do limite.

A surpresa está, talvez, na observação de que a sala de espera é mais ruidosa do que a de atendimento, mesmo com o uso da caneta de alta rotação. Isso se deve ao ruído provocado pela TV, pela conversação entre os pacientes em espera e, principalmente, pelo ambiente externo.

Note-se que o ruído externo chega à janela da sala de atendimento com $68 \mathrm{~dB}$, enquanto próximo à caneta de alta rotação o ruído é de aproximadamente $66 \mathrm{~dB}$. 


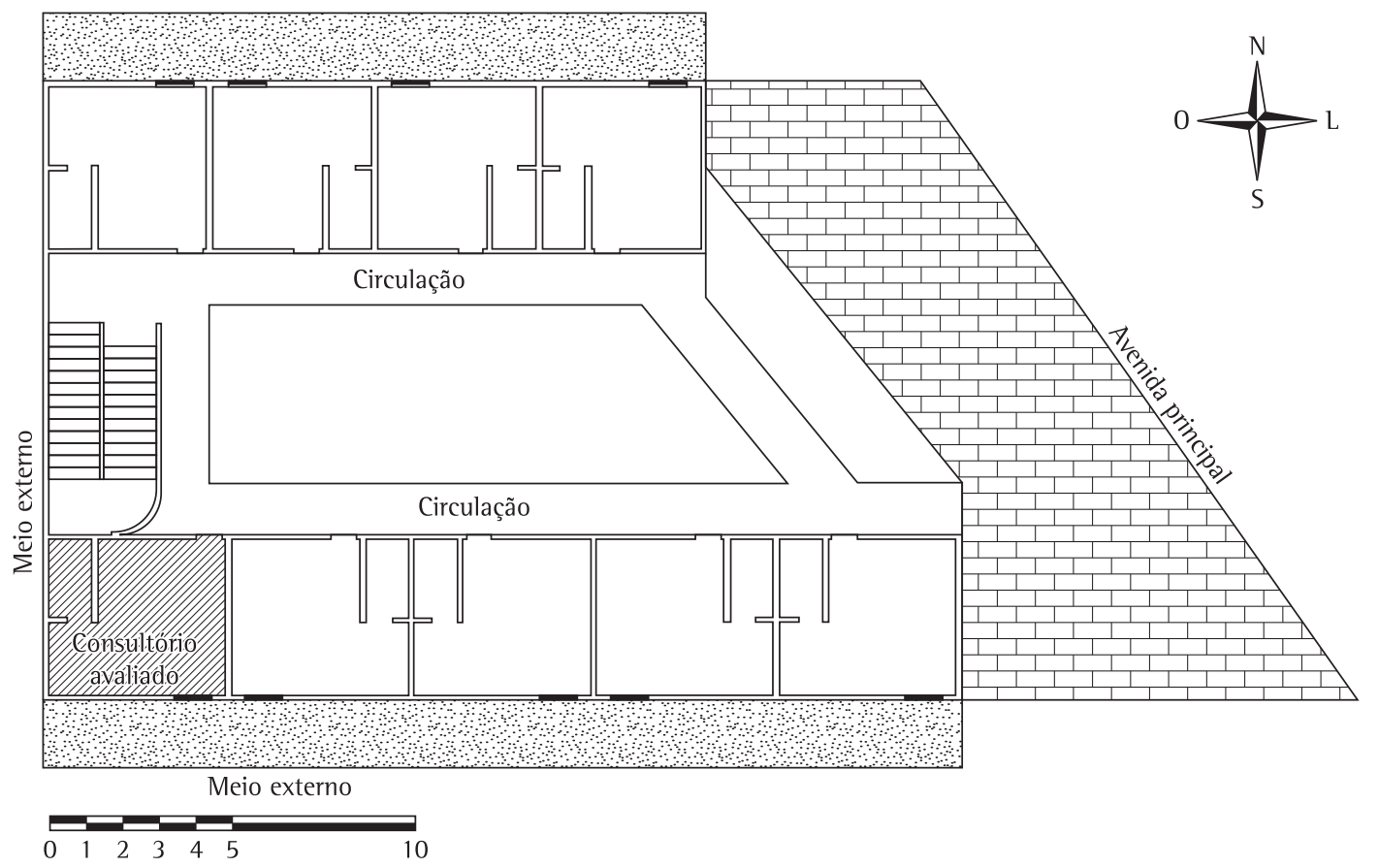

Figura 4. Localização da edificação e do consultório avaliado.

\subsection{Cálculo de isolamento acústico e tempo de reverberação}

Os cálculos de isolamento acústico reforçaram os resultados obtidos através das medições. Guardem-se, no entanto, as diferenças devidas à precisão dos dados referentes ao índice de isolamento acústico (IA) obtido na literatura e ao IA real dos materiais existentes, e às frequências do som não medidas em campo.

Na sala de espera, observa-se que sua envoltória tem a capacidade de reduzir o ruído externo (RR) cerca $12,72 \mathrm{~dB}$, o som, na frequência de $125 \mathrm{~Hz}$, e aproximadamente $14 \mathrm{~dB}$, nas frequências de 500 e $2000 \mathrm{~Hz}$, indicando um desempenho levemente superior para frequências mais altas (Tabela 3). 0 mesmo ocorre na sala de atendimento, entretanto com maior eficiência, já que a porta e a janela permanecem fechadas (Tabela 3).

Para essas condições, o ruído máximo aceitável externamente seria de 67,7 a $69,45 \mathrm{~dB}$ em relação à sala de espera (Tabela 3) e de 72,8 a 79,2 dB (Tabela 3) na sala de atendimento, dependendo da frequência do som. Como o nível de ruído medido na rua superou os $84 \mathrm{~dB}$, percebe-se o baixo desempenho da envoltória.

Para corrigir essa deficiência, sugeriu-se aplicar um reboco de vermiculite nas paredes, retirar os tijolos de vidro existentes na divisória que separa as duas salas e fechar a porta de acesso ao consultório,

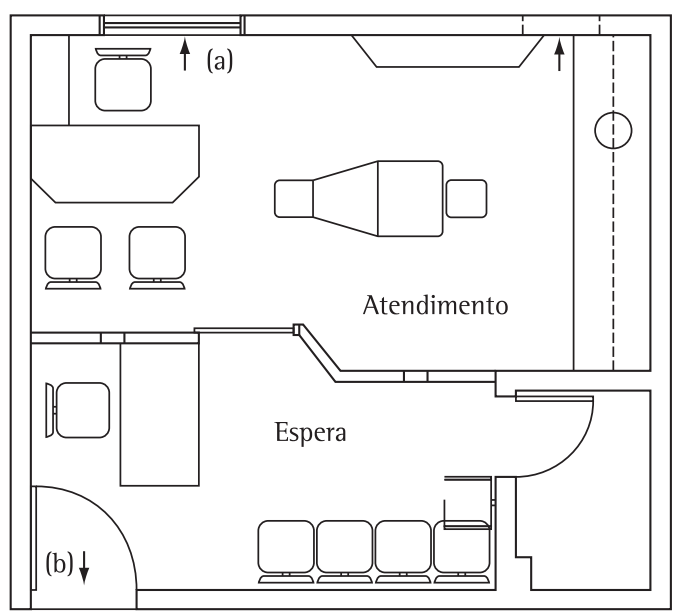

Figura 5. Pontos vulneráveis à penetração de ruídos externos.

por onde penetra a maior parte do ruído proveniente do exterior. Para isso, será necessária a instalação de um aparelho de ar-condicionado na sala de espera, indicando-se assim um modelo split, mais silencioso e mais econômico em termos de consumo de energia elétrica. Essas modificações foram suficientes para se atingir o isolamento necessário, como pode ser verificado na Tabela 3, na coluna "Depois".

Outro fator importante na avaliação acústica é o tempo de reverberação, que indica o tempo da 
Tabela 2. Níveis de ruído medidos em campo.

\begin{tabular}{|c|c|c|c|c|}
\hline \multirow{2}{*}{ Condição } & \multicolumn{2}{|c|}{ Fonte } & \multicolumn{2}{|c|}{ Interesse } \\
\hline & Local & Ruido (dBA) & Local & Ruído (dBA) \\
\hline $\begin{array}{l}\text { Sala de espera com todos os equipamentos ligados e sala de } \\
\text { atendimento inativa }\end{array}$ & $\begin{array}{l}\text { Porta da sala de } \\
\text { atendimento }\end{array}$ & 73,9 & $\begin{array}{l}\text { Porta da sala de } \\
\text { espera }\end{array}$ & 74,0 \\
\hline $\begin{array}{l}\text { Sala de atendimento com todos os equipamentos ligados e } \\
\text { sala de espera inativa }\end{array}$ & $\begin{array}{l}\text { Caneta de alta } \\
\text { rotação }\end{array}$ & 65,7 & Janela & 68,0 \\
\hline $\begin{array}{l}\text { Sala de espera e sala de atendimento com equipamentos } \\
\text { ligados e com ruído da rua }\end{array}$ & Sala de espera & 79,0 & Sala de atendimento & 73,0 \\
\hline $\begin{array}{l}\text { Sala de espera com equipamentos desligados e com ruído } \\
\text { da rua }\end{array}$ & Rua & 84,4 & $\begin{array}{l}\text { Centro da sala de } \\
\text { espera }\end{array}$ & 74,5 \\
\hline $\begin{array}{l}\text { Sala de atendimento com equipamentos desligados e com } \\
\text { ruído da rua }\end{array}$ & Rua & 84,9 & $\begin{array}{l}\text { Centro da sala de } \\
\text { atendimento }\end{array}$ & 55,0 \\
\hline \multirow{2}{*}{$\begin{array}{l}\text { Sala de espera e sala de atendimento com equipamentos } \\
\text { ligados e sem ruído externo }\end{array}$} & $\begin{array}{l}\text { Atendimento/ } \\
\text { Caneta ligada }\end{array}$ & 73,0 & \multirow{2}{*}{ Sala de espera } & \multirow{2}{*}{67,8} \\
\hline & $\begin{array}{l}\text { Sala atendimento/ } \\
\text { Caneta desligada }\end{array}$ & 58,0 & & \\
\hline
\end{tabular}

Tabela 3. Isolamento acústico em dB.

\begin{tabular}{|c|c|c|c|c|c|c|}
\hline \multirow{3}{*}{ Isolamento acústico } & \multicolumn{6}{|c|}{ Frequência } \\
\hline & \multicolumn{2}{|c|}{$125 \mathrm{~Hz}$} & \multicolumn{2}{|c|}{$500 \mathrm{~Hz}$} & \multicolumn{2}{|c|}{$2000 \mathrm{~Hz}$} \\
\hline & Antes & Depois & Antes & Depois & Antes & Depois \\
\hline \multicolumn{7}{|l|}{ Sala de espera } \\
\hline Redução de ruído (RR) em dB & 12,72 & 19,37 & 14,28 & 30,24 & 14,45 & 42,91 \\
\hline Nível de ruído máximo aceitável internamente & 55,00 & 55,00 & 55,99 & 55,00 & 55,00 & 55,00 \\
\hline Máximo nível de ruído aceitável externamente & 67,73 & 74,37 & 69,28 & 85,24 & 69,45 & 97,91 \\
\hline \multicolumn{7}{|l|}{ Sala de atendimento } \\
\hline Redução de ruído (RR) em dB & 17,86 & 19,94 & 23,40 & 31,03 & 24,22 & 43,65 \\
\hline Nível de ruído máximo aceitável internamente & 55,00 & 55,00 & 55,00 & 55,00 & 55,00 & 55,00 \\
\hline Máximo nível de ruído aceitável externamente & 72,86 & 74,94 & 78,40 & 86,03 & 79,22 & 98,65 \\
\hline
\end{tabular}

Tabela 4. Reverberação.

\begin{tabular}{|c|c|c|c|c|c|c|}
\hline \multirow{3}{*}{ Reverberação } & \multicolumn{6}{|c|}{ Frequência } \\
\hline & \multicolumn{2}{|c|}{$125 \mathrm{~Hz}$} & \multicolumn{2}{|c|}{$500 \mathrm{~Hz}$} & \multicolumn{2}{|c|}{$2000 \mathrm{~Hz}$} \\
\hline & Antes & Depois & Antes & Depois & Antes & Depois \\
\hline \multicolumn{7}{|l|}{ Sala de espera } \\
\hline Absorção total calculada & 2,41 & 8,36 & 3,13 & 12,31 & 3,61 & 16,32 \\
\hline Absorção ideal & 8,87 & 2,29 & 13,04 & 12,18 & 13,04 & 12,18 \\
\hline Tempo de reverberação calculado (tr), em s & 1,08 & 0,29 & 0,83 & 0,20 & 0,72 & 0,15 \\
\hline \multicolumn{7}{|l|}{ Sala de atendimento } \\
\hline Absorção total calculada & 3,29 & 13,66 & 4,17 & 23,69 & 4,77 & 28,57 \\
\hline Absorção ideal & 16,10 & 4,98 & 23,67 & 22,51 & 23,67 & 22,51 \\
\hline Tempo de reverberação calculado (tr), em s & 1,44 & 0,33 & 1,14 & 0,19 & 0,99 & 0,16 \\
\hline
\end{tabular}

permanência do som se propagando no ambiente. No caso de consultórios odontológicos, o tempo de reverberação deve ser o menor possível, para que os ruídos produzidos pelos equipamentos odontológicos sejam absorvidos em maior quantidade e em menor tempo possivel.

Nos dois ambientes analisados, o tempo de reverberação é elevado, chegando a mais de 1 segundo, principalmente nas baixas frequências (Tabela 4). Tal situação requer a substituição dos materiais das superfícies por outros mais absorventes, se possivel, com maior eficiência nas altas frequências, devido ao ruído provocado pelos equipamentos odontológicos. As modificações sugeridas (descritas na análise do isolamento acústico) proporcionaram a redução do tempo de reverberação para no máximo 0,3 segundos na frequência de $125 \mathrm{~Hz}$, na sala de espera, e para 0,15 e 0,16 segundos na frequência de $2000 \mathrm{~Hz}$, nas salas de espera e de atendimento respectivamente. 


\section{Conclusões}

Os resultados obtidos neste trabalho, além de indicar o baixo desempenho acústico do ambiente e a consequente situação de desconforto em que se encontram seus usuários, revelam a importância do projeto de arquitetura na qualidade do ambiente de trabalho. Desconsiderar os princípios de qualidade ambiental na concepção do projeto pode trazer consequências nocivas à saúde das pessoas, repercutindo na sua produtividade e qualidade de vida.

A dificuldade de adequar um consultório odontológico aos níveis aceitáveis de ruído está em diversos fatores, a começar pela sua localização no espaço urbano, considerando que muitos deles se situam em locais de grande fluxo de veículos. Outro fator é a escolha dos tipos de materiais a serem utilizados, principalmente na sala de atendimento. Como se trata de um ambiente clínico, as exigências de assepsia tornam necessário o uso de materiais mais densos, com pouca porosidade, o que os torna mais reflexivos ao som. Por fim, está nos tipos de equipamentos utilizados, em geral muito ruidosos, requerendo a utilização de protetores auriculares por parte dos profissionais.

No caso particular estudado, essas dificuldades, associadas a um projeto inadequado à atividade desenvolvida no ambiente, forçam intervenções, até certo ponto, onerosas, se for considerado o padrão do consultório estudado, que possui faturamento relativamente baixo. A principal delas é a instalação de mais um aparelho de ar-condicionado, que aumentará o custo fixo do negócio. Tal alternativa poderia ser evitada na fase de projeto e/ou no planejamento do consultório, a partir da escolha do local mais apropriado para a sua instalação.
A inteligibilidade da voz nesses ambientes foi considerada de menor importância nessa pesquisa, visto que a proximidade entre o profissional e o paciente pode suprimir o sombreamento da voz pelos ruídos de fundo provocados pelos equipamentos.

\section{Referências}

ASSOCIAÇÃO BRASILEIRA DE NORMAS TÉCNICAS - ABNT. NBR 10152: Níveis de ruído para conforto acústico. Rio de Janeiro, 1997.

BARROS, 0. B. Ergonomia 1: a eficiência ou rendimento e a filosofia correta de trabalho em odontologia. São Paulo: Pancast, 1991.

BERTOLI, S. R.; CARNEIRO, A. R. Desempenho acústico de consultórios odontológicos. Acústica, p. 1-8, 2004.

CARVALHO, R. P. Acústica arquitetônica. Brasília: Thesaurus, 2006.

IIDA, 1. Ergonomia: projeto e produção. 2. ed. São Paulo: Lucher, 2005.

LACERDA, A. et al. Nível de pressão sonora de um consultório odontológico: uma análise ergonômica. Tuluti: Ciência e Cultura, n. 26, p. 17-24, 2002.

NORMA Regulamentadora n. 15: atividades e operações insalubres. Brasília, 1978.

NORMA Regulamentadora n. 17: Ergonomia. Brasília, 1990.

PARAgUAY, A. T. T. Perda auditiva induzida por ruído em consultório odontológico. 1999. 79 f. Trabalho de Conclusão de Curso (Fonoaudiologia)-Cefac, Recife, 1999.

SÃO PAULO (Estado). Secretaria de Saúde. Norma: uma técnica que dispõe sobre o diagnóstico de perda auditiva induzida por ruído e a redução e controle do ruído nos ambientes e postos de trabalho. São Paulo, 1994.

TÔRRES, B. 0. A Perda Auditiva Induzida pelo Ruído (PAIR) na formação odontológica: conhecimentos e níveis de exposição. 2007. Dissertação (Mestrado em Odontologia)-Universidade Federal do Rio Grande do Norte, UFRN, Natal, 2007.

\title{
Evaluation of acoustic performance of a dental office
}

\begin{abstract}
This work analyses the acoustic comfort of a dentistry clinic located João Pessoa, considering several situations of use of the space. It was developed through a physical survey of the place (dimensions and materials), identification of the performed activities, identification external and internal sources of noise and measurement of the noise levels. The noise levels measured were compared with the NBR 10.152 (ABNT, 1987) norm standards. Soon after, the isolation and the time of reverberation were calculated in order to solve the problem. The results show that the clinic is uncomfortable because it does not meet the acoustic standards of the norms.
\end{abstract}

\section{Keywords}

Acoustics comfort. Clinic. Acoustic isolation. Reverberation. 